Casos Clínicos

\title{
Tumor de células de la granulosa asociado hiperandrogenismo femenino rápidamente progresivo
}

\author{
Adriana Doren ${ }^{1,3}$, Constanza Ralph ${ }^{1}$, Paulina Villaseca ${ }^{2}$, Jorge Brañes ${ }^{1}$, \\ Rodrigo Macaya. 1 \\ ${ }_{3}^{1}$ División de Obstetricia y Ginecología, ${ }^{2}$ Departamento de Endocrinología, Pontificia Universidad Católica de Chile. \\ 3 Departamento Obstetricia y Ginecología, Hospital Regional de Talca.
}

\section{RESUMEN}

Reportamos el caso de una mujer de 21 años con hiperandrogenismo rápidamente progresivo de origen tumoral ovárico. La biopsia informó tumor de células de la granulosa y la resección fue curativa. Se analizan los posibles mecanismos por los que un tumor de origen en células de la granulosa pueda sintetizar andrógenos.

\section{PALABRAS CLAVE: Hiperandrogenismo, tumor de células de la granulosa, tumor ovárico funcional}

\section{SUMMARY}

We report a 21 year old woman with rapidly progressive hyperandrogenism of ovaric tumoral origin. The biopsy of the tumor reported a granulosa cell tumor and the surgery was curative. We analyze the possible mechanisms implied in the androgen production in the granulosa cells of the tumor.

\section{KEY WORDS: Hyperandrogenism, granulosa cell tumor, ovarian functional tumor}

\section{INTRODUCCIÓN}

En mujeres, el hiperandrogenismo de inicio súbito, rápidamente progresivo, con o sin signos de virilización, en presencia de altos niveles de testosterona total y/o índice de andrógenos libres (IAL), debe hacer buscar un tumor ovárico o suprarrenal productor de andrógenos (1-3).

En la mujer, los tumores ováricos hormonalmente activos constituyen los llamados tumores del estroma del cordón sexual. Éstos se componen de células derivadas de cordones sexuales o del mesénquima de las gónadas embrionarias y contienen, en conjunto o por separado, células de la granulosa, células de Sertoli, células de Leydig y células de la teca (4). Sin embargo, los tumores virilizantes son una causa poco frecuente de hiperandrogenismo en la mujer y constituyen menos del $5 \%$ de las neoplasias ováricas (5).

El tumor de células de la granulosa (TCG) es el tumor ovárico del estroma gonadal específico más prevalente y su forma de manifestación habitual es con aumento de los niveles de estrógenos circulantes $(6,7)$. Se han reportado casos de TCG 
asociados a virilización, siendo más frecuente esta manifestación en la forma adulta de este tumor que en la juvenil (8-10).

El objetivo de esta comunicación es reportar un caso de tumor de las células de la granulosa expresado por hiperandrogenismo en una mujer en edad fértil.

\section{Caso clínico}

Mujer de 21 años, nuligesta, evaluada en la unidad de Endocrinología Ginecológica por polimenorrea de 5 meses de evolución, descrita como menstruaciones de 5 días de duración y ciclos de 15 días. Con historia de desarrollo puberal normal y menarquia a los 12 años. Entre sus antecedentes destacaba el diagnóstico de Síndrome de Ovario Poliquístico (SOP) y resistencia a la insulina diagnosticados a los 17 años, en tratamiento con metformina desde entonces. Sin otros antecedentes personales ni familiares relevantes.

En el examen físico de la primera consulta destacaba acné leve facial, sin evidenciarse hirsutismo, cliteromegalia, ni otros hallazgos patológicos (se omitió examen ginecológico por no haber iniciado actividad sexual), no se evidenciaron tumores en la palpación abdominal. Su índice de masa corporal era normal. El estudio de laboratorio mostró: testosterona total $6,15 \mathrm{nmol} / \mathrm{L}(177,37 \mathrm{ng} /$ dl), SHBG 25,5 nmol/L, 17-OH-progesterona basal normal, índice de andrógenos libres (IAL) 24,1, TTGO con $75 \mathrm{~g}$ de glucosa normal y curva de insulina basal 3,3 uUl/mL y post carga de 71,2 uUl/ $\mathrm{mL}$ (usando metformina).

En control a los 30 días la paciente describe crecimiento rápido del pelo y aumento del vello corporal. Resto del examen físico sin cambios respecto a la consulta previa. La ecografía pelviana demostró en el ovario izquierdo un tumor sólido de $53 \times 37 \times 43 \mathrm{~mm}$, de bordes bien delimitados, con ecos heterogéneos en su interior (Figura 1); tanto el ovario derecho como el endometrio fueron descritos dentro de límites normales.

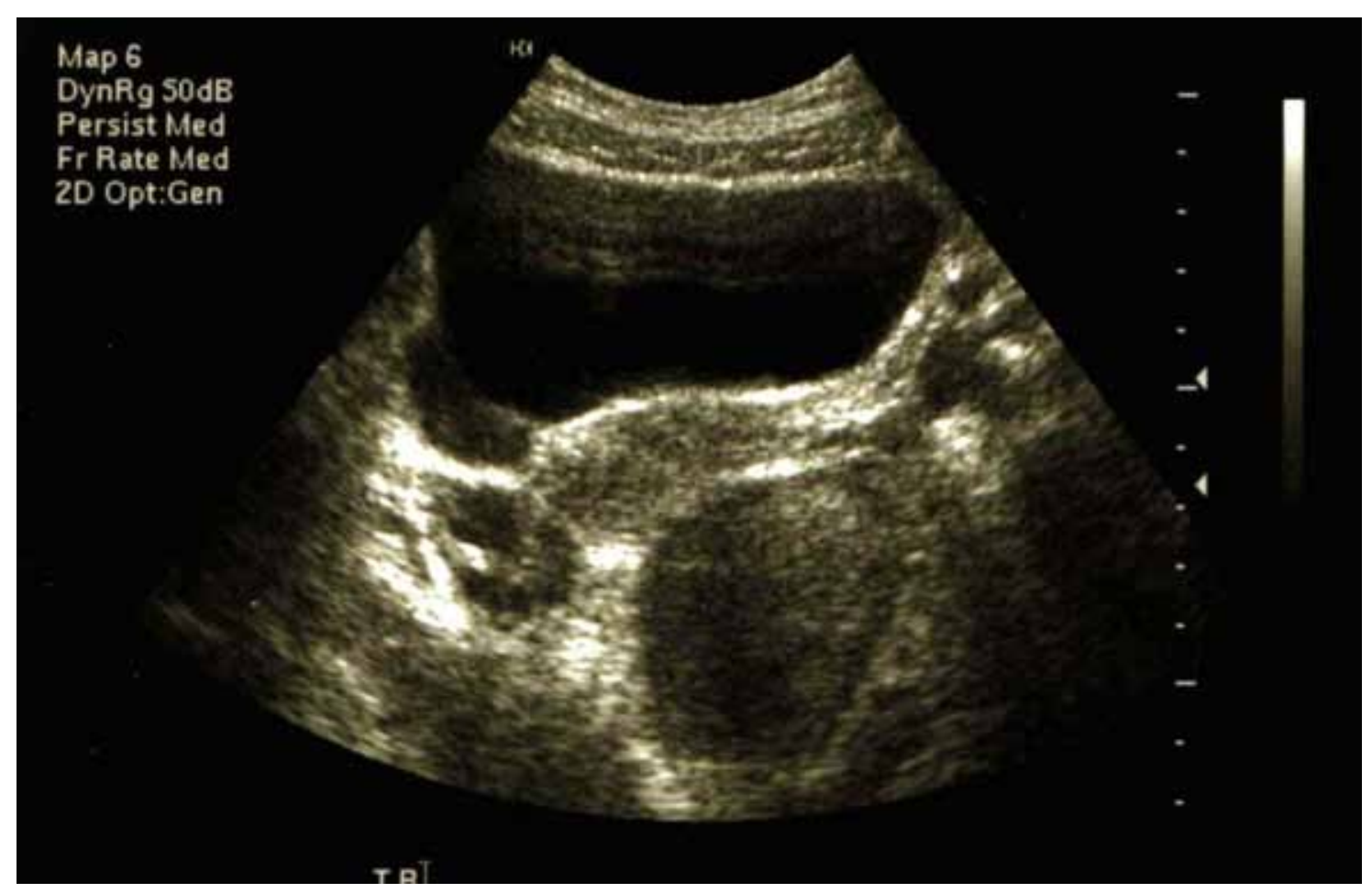

Figura 1. Ecografía ginecológica que muestra tumor sólido ovárico izquierdo de 53 × 37 x 43 mm 
Se realizó una tumorectomía laparoscópica, destacando como hallazgo intraoperatorio un tumor ovárico de bordes lisos y contenido sólido amariIlento (Figura 2 y 3 ). El diagnóstico histopatológico en nuestra institución fue: tumor fuso celular del estroma especializado del ovario, sugiriendo células de la granulosa como primera posibilidad y células de Sertoli como segunda alternativa, destacando

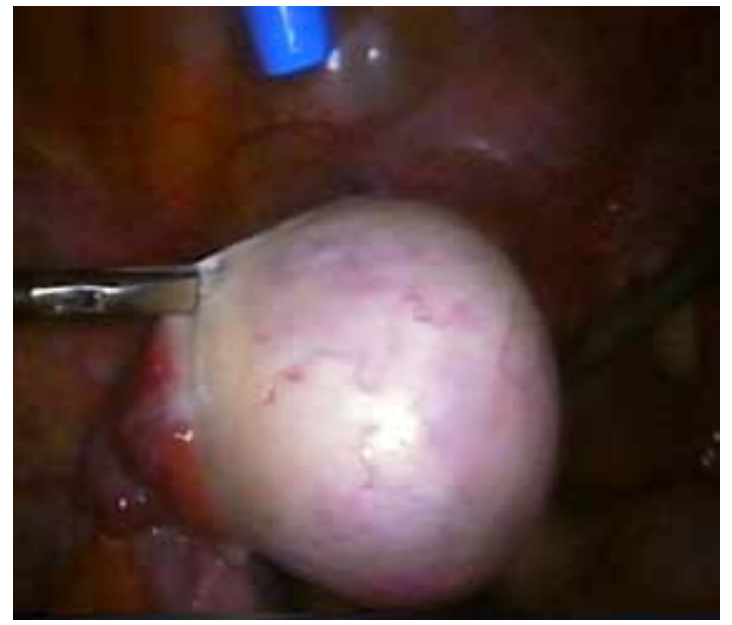

Figura 2. Visualización laparoscópica de tumor ovárico izquierdo. una reacción inmunohistoquímica positiva intensa para inhibina en las células tumorales y positiva leve para pancitoqueratina. Una nueva revisión de la biopsia informó fibroma celular, por lo que se decidió enviar las muestras a la Universidad de Harvard, donde se demostró que correspondía a un tumor de células de la granulosa (Figura 4).

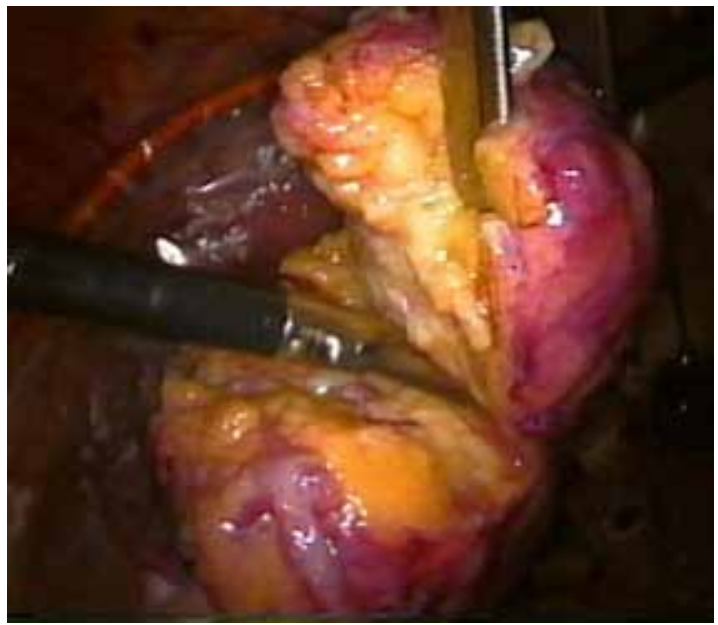

Figura 3. Apertura controlada del tumor en endobag durante la laparoscopía.

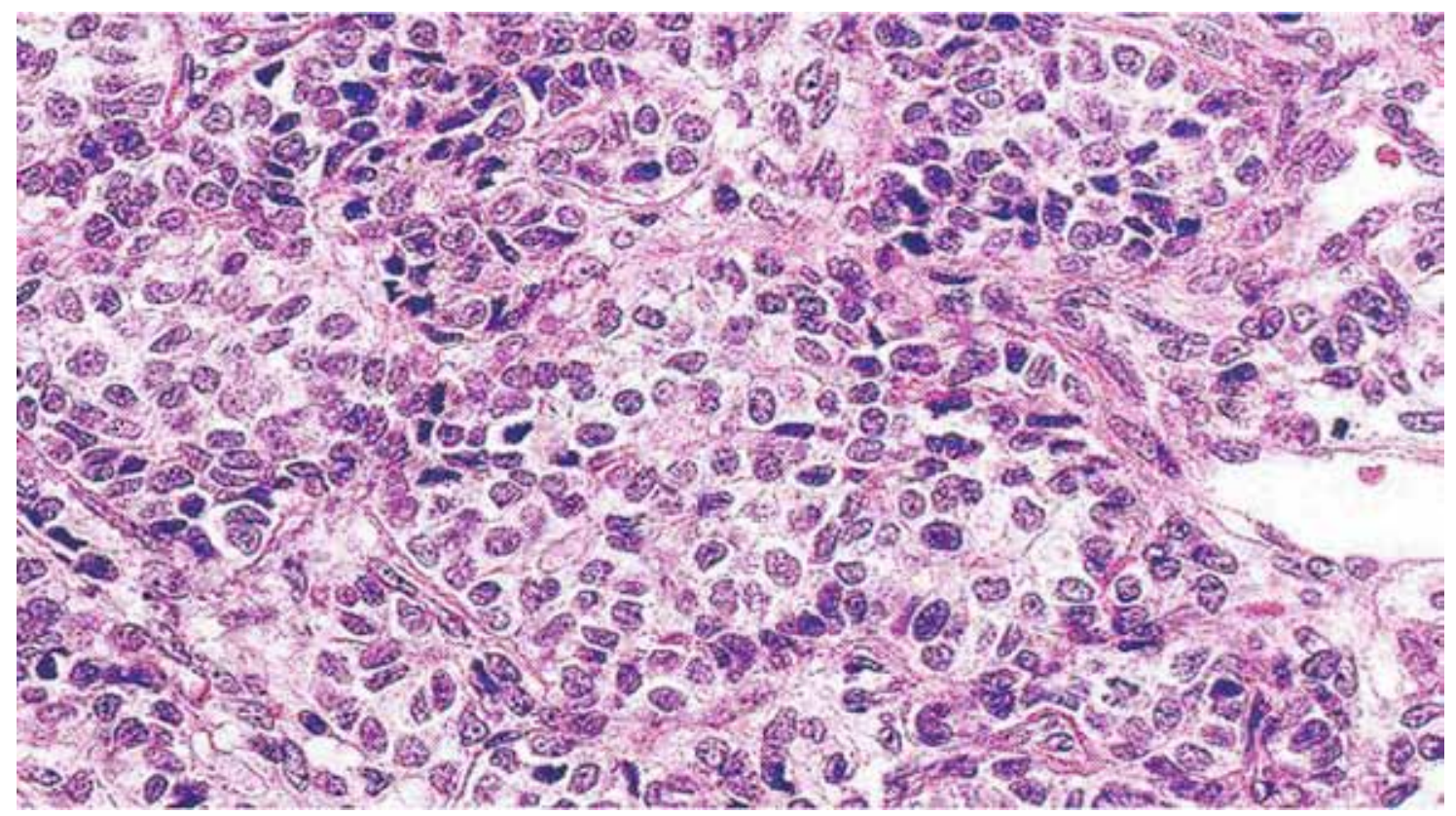

Figura 4. Histología de tumor de células de la granulosa (Gentileza de CEPACSE: Centro de Patología y Citología Sevilla. http://www.cepacse.es/caso/038.htm). 
Siendo que el tratamiento de estos tumores es exclusivamente quirúrgico, se procedió a completar el tratamiento con una salpingo-ooforectomía ipsilateral y etapificación quirúrgica, descartándose enfermedad residual en el anexo y en ganglios paraaórticos y pelvianos.

La evolución postoperatoria fue con regresión rápida del hiperandrogenismo y de los andrógenos circulantes: testosterona total $1,32 \mathrm{nmol} / \mathrm{L}(38,06$ $\mathrm{ng} / \mathrm{dL}$ ), SHBG $38 \mathrm{nmol} / \mathrm{L}$, IAL 3,5. La paciente recuperó menstruaciones regulares a los tres meses de la cirugía. Sin evidencia tumoral hasta la fecha, con seguimiento semestral ecográfico y con estradiol sérico dentro de límites normales.

\section{DISCUSIÓN}

Los TCG suelen manifestarse por hiperestrogenismo, y su asociación a aumento de los niveles circulantes de andrógenos e hiperandrogenismo clínico es poco frecuente (6-10).

La fisiopatología del hiperandrogenismo en los TCG aún no ha sido explicada, pero se han propuesto varios mecanismos que podrían explicar este escenario clínico (8). Una de las propuestas es la luteinización del estroma ovárico producida por la presión ejercida por la acumulación de líquido dentro del quiste $(9,10)$. Sin embargo, las células de la teca luteinizadas producirían androstenodiona, un andrógeno débil que las células de la granulosa convertirían en estradiol, por lo que esta teoría sería insuficiente para explicar la androgenización de la paciente afectada (11).

Otro mecanismo involucrado ha sido la expresión aberrante de la proteína SOX9 ("SRY box-9") (12), un efector del factor determinante testicular SRY (sex-determining region $Y$ ), que juega un rol esencial en la diferenciación de los cordones testiculares (8). Sin embargo, esta asociación no ha podido ser demostrada, pues se ha descrito la expresión de SOX9 en TCG con hiperandrogenismo asociado y en TCG de manifestación habitual (8).

Por otro lado, el factor de transcripción FOXL2 ("Fork head box protein L2") es un regulador de la organogénesis del ovario y es esencial para el desarrollo de la gónada femenina y en la diferenciación de las células de la granulosa durante la foliculogénesis (13-16). Es habitual en los TCG la expresión aberrante del FOXL2, pudiendo identificarse una mutación somática en el 97\% del TCG tipo adulto y en el $10 \%$ del tipo juvenil $(17,18)$. Es por esto que una hipótesis planteada para el hiperandrogenismo asociado a TCG sería la ausencia del factor FOXL2 (12), esto debido a observaciones de ratones knock-out para FOXL2 en los que se ha inducido una transdiferenciación de tejido ovárico a tejido testicular (19). Sin embargo, esta inactividad del FOXL2 en los TCG con hiperandrogenismo tampoco ha logrado demostrarse al grado de explicar en su totalidad la virilización infrecuentemente asociada a estos tumores (8).

Otro posible mecanismo de hiperandrogenismo publicado es la expresión disminuida de aromatasa intratumoral con subsecuente reducción de la conversión de andrógenos a estrógenos, defecto que ha sido demostrado en el $100 \%$ de los TCG asociados a hiperandrogenismo (8). Es así como la pregnenolona producida por las células tumorales sería metabolizada a andrógenos por las células estromales, y dichas hormonas masculinas se acumularían al no ser aromatizadas a estrógeno por las células tumorales enzimáticamente defectuosas. Esta alteración en la aromatasa tumoral puede explicarse por el grado de indiferenciación de las células de la granulosa del tumor.

\section{CONCLUSIÓN}

Presentamos un caso de TCG asociado a hiperandrogenismo rápidamente progresivo que revirtió en su totalidad con la extirpación del tumor, y que nos plantea la interrogante acerca de los mecanismos asociados a esta infrecuente forma de presentación de los TCG, mecanismos que si bien han sido extensamente estudiados no se ha logrado encontrar una respuesta definitiva.

AGRADECIMIENTOS: A CEPACSE, Centro de Patología y Citología Sevilla, España, por autorizar publicación de imagen histológica, debido a extravío de nuestra muestra y permitir hacer más didáctica nuestra presentación.

\section{REFERENCIAS}

1. Outwater EK, Wagner BJ, Mannion C, MClarney JK, Kim B. Sex cord-stromal and steroid cell tumors of the ovary.Radiographics 1998;18(6):1523-46.

2. Varras M, Vasilakakl T, Skafida E, Akrivis C. Clinical, ultrasonographic, computed tomography and histopathological manifestations of ovarian steroid cell tumour, not otherwise specified: our experience of a rare case with female virilisation and review of the literature. Gynecol Endocrinol 2011;27(6):412-8.

3. Moreno S, Montoya G, Armstrong J, Leteurtre E, Aubert S, Vantyghem MC, et al. Profile and outcome of pure androgen-secreting adrenal tumors in women: experience of 21 cases. Surgery. 2004; 136(6):1192-8.

4. Stegner HE, Loning T. Endocrine-active tumors of the ovary. Pathologe. 2003;24: 314-22 
5. Faraj G, Di Gregorio S, Misiunas A, Faure A, Villabrile $P$, Stringa I, et al. Virilizing ovarian tumor of cell type not otherwise specified: a case report. Gynecol Endocrinol1998; 12: 347-52.

6. Evans AT 3rd, Gaffey TA, Malkasian GD JR, Annegers JF. Clinico pathologic review of 118 granulosa and 82 theca cell tumors. Obstet Gynecol 1980;55(2):231-38.

7. Young RH. Sex cord-stromal tumors of the ovary and testis: their similarities and differences with consideration of selected problems. Mod Pathol. 2005;18 (Suppl 2):S81-98.

8. Kalfa N, Méduri G, Philibert P, Patte C, Boizet-Bonhoure $\mathrm{B}$, Thibaut $\mathrm{E}$, et al. Unusual virilization in girls with juvenile granulosa cell tumors of the ovary is related to intratumoral aromatase deficiency. Horm Res Paediatr2010;74(2): 83-91.

9. Nakashima N, Young RH, Scully RE. Androgenic granulosa cell tumors of the ovary: a clinic pathologic analysis of 17 cases and reviewof the literature. Arch Pathol Lab Med1984; 108: 786-791.

10. Martinez L, Salmeron M, Carvia RE, Campello TR, Molina R, Herruzo AJ, et al. Androgen producing luteinized granulosa cell tumor. Acta ObstetGynecolScand 1997; 76: 285-286.

11. Gershenson DM.Sex cord-stromal tumors of the ovary: Granulosa-stromal cell tumors. 2013 UpToDate.
12. Kalfa N, Fellous M, Boizet-Bonhoure B, Patte C, Duvillard $\mathrm{P}$, Pienkowski $\mathrm{C}$, et al. Aberrant expressionof ovary determining gene foxl2 in thetestis and juvenile granulosa cell tumor inchildren. J Urol 2008; 180: 1810-1813.

13. Prueitt RL, Zinn AR.A fork in the road tofertility. Nat Genet 2001; 27: 132-134.

14. Cocquet J, De Baere E, Gareil M, Pannetier M, Xia X, Fellous M, Veitia RA. Structure, evolution and expression of the Foxl2 transcriptionunit. Cytogenet Genome Res 2003;101: 206-211.

15. Jaubert F, Galmiche L, Lortat-Jacob S, Fournet JC, Fellous M. Foxl-2 in gonad development and pathology. ArkhPatol 2011; 73(4): 10-13.

16. Pisarka MD, Barlow G, Kuo FT. Minireview: roles of forkhead transcription factor FOXL2 in granulosa cell biology and pathology. Endocrinology 2011; 152(4): 1199-1208.

17. Shah SP, Köbel M, Senz J, Morin R, Clarke B, Wiegand $\mathrm{K}$, et al. Mutation of FOXL2 in granulosa-cell tumors of the ovary. N Engl J Med 2009; 360:2719-29.

18. Köbel M, Gilks CB, Huntsman DG. Adult-type granulosa cell tumors and FOXL2 mutation. Cancer Res 2009; 69:9160-2.

19. Verdin H, De Baere E. FOXL2 impairment in human disease. Horm Res Paediatr 2012; 77(1): 2-11. 